www.nature.com/pj

\title{
Synthesis of thermoresponsive polysilsesquioxane with methoxyethylamide group and crown ether
}

\author{
Tomonori Matsuoka $^{1}$, Shin-ichi Yamamoto ${ }^{1}$, Osamu Moriya ${ }^{1}$, Mikihiro Kashio ${ }^{2}$ and Toshio Sugizaki ${ }^{2}$ \\ A polysilsesquioxane with a bis(2-methoxyethyl)amide group and 15-crown-5-ether ring (MCPSQ) was newly prepared by \\ the co-condensation of silane coupling reagents, which were obtained from (3-isocyanatopropyl)triethoxysilane and the \\ corresponding amines with the respective groups. MCPSQ showed the expected amphiphilic and thermoresponsive properties. \\ The behaviors of hydrophobic aggregation of MCPSQ in the aqueous solutions containing the chlorides of lithium, potassium \\ and sodium reflected the selective ion recognition property due to the presence of the crown ether. The highest aggregation \\ temperature of $32{ }^{\circ} \mathrm{C}$ was observed in the solution containing sodium ion as expected from the coordination ability of the crown \\ ether group. With the use of the sodium salt of 4-phenylazobenzoic acid as an additive in the aqueous solution of MCPSQ, the \\ aggregation temperature was changed according to the photochemical isomerization of the phenylazobenzoate group. The results \\ show the efficient coordination of the sodium salt with the crown ether ring.
}

Polymer Journal (2010) 42, 313-318; doi:10.1038/pj.2010.7; published online 3 March 2010

Keywords: crown ether; phase separation; photoresponsive isomerization; polysilsesquioxane; thermoresponsive hybrid

\section{INTRODUCTION}

Polysilsesquioxane (PSQ) is a new member of the group of silicones. ${ }^{1-4}$ The main chain of PSQ is reported to consist mainly of T-type siloxane units. $^{5-8}$ PSQ has been investigated for possible applications in various contexts, such as electrical, optical, mechanical and chemical uses. ${ }^{9-11}$ This range of applications is made possible by the modification of the organic functional group, which is contained in the starting trialkoxyor trichlorosilanes. Graft polymerizations onto and from the PSQ main chain are one of the most effective methods of making modifications, in which the polymeric component provides an additional property besides durability for heat and weatherability based on the inorganic polysiloxane backbone. ${ }^{12-16}$ Among the various functions conferred on the hybrids on the basis of their polysiloxane structure, thermoresponsive phase separation in an aqueous solution is one of the useful properties. This property is required of materials used for microencapsulation, biosensors, drug delivery and so forth, as reported in a variety of recent works. ${ }^{17-23}$ Owing to the interest in such applications, we have investigated the graft polymerization of $N$-isopropylacrylamide. ${ }^{24-26}$ Through the grafting of the polymeric component, the resulting PSQ successfully exhibited a thermoresponsive property in an aqueous solution. Although the corresponding functionalized gel is known to be useful and a convenient hybrid, PSQ soluble in a usual solvent could be used in a wide range of applications.

Investigations into thermoresponsive materials have now advanced to the stage of providing multiple stimulus-responsive properties such as $\mathrm{pH}$, photo and ion recognition. ${ }^{27-37}$ The use of PSQ seems to be convenient for the introduction of such additional responsive func- tions. In particular, the silane coupling reagent with the low-molecular-weight organic group, which provides the thermoresponsive property, is expected to be a more useful material for the formation of the multi-functional PSQ. Such a silane coupling reagent can directly form the multi-stimulus-responsive PSQs by the combination of other silane coupling reagents. In addition, the procedure does not require modification to the initiator species or the grafting of the polymeric component on the PSQ main chain, both of which usually require treatment under an inert gas. Therefore, we have initiated an investigation of the use of the silane coupling reagent as a building block to prepare thermoresponsive PSQ.

Various synthetic polymers have been known to show a thermoresponsive property in an aqueous solution. ${ }^{38-42}$ Most of these polymers possess the hydrophilic ethyleneoxy or amide group with a hydrophobic alkyl group. This fact led us to design the silane coupling reagents to have alkoxyethylamide groups. Such coupling reagents were presumed to be obtained readily from the simple addition reaction of the amines to (3-isocyanatopropyl)triethoxysilane and transformed into the PSQs through a condensation reaction. In fact, as reported in a previous work, the use of the silane coupling reagents caused the PSQs to show the expected amphiphilicity and thermoresponsive property in an aqueous solution. ${ }^{43}$ The lower critical solution temperature (LCST) of the obtained PSQs could be controlled by the hydrophobic alkyl groups.

In studies using the silane coupling reagents with the alkoxyethylamide groups, co-condensation with various silane coupling reagents has been continuously used to create the multi-stimulus-responsive 


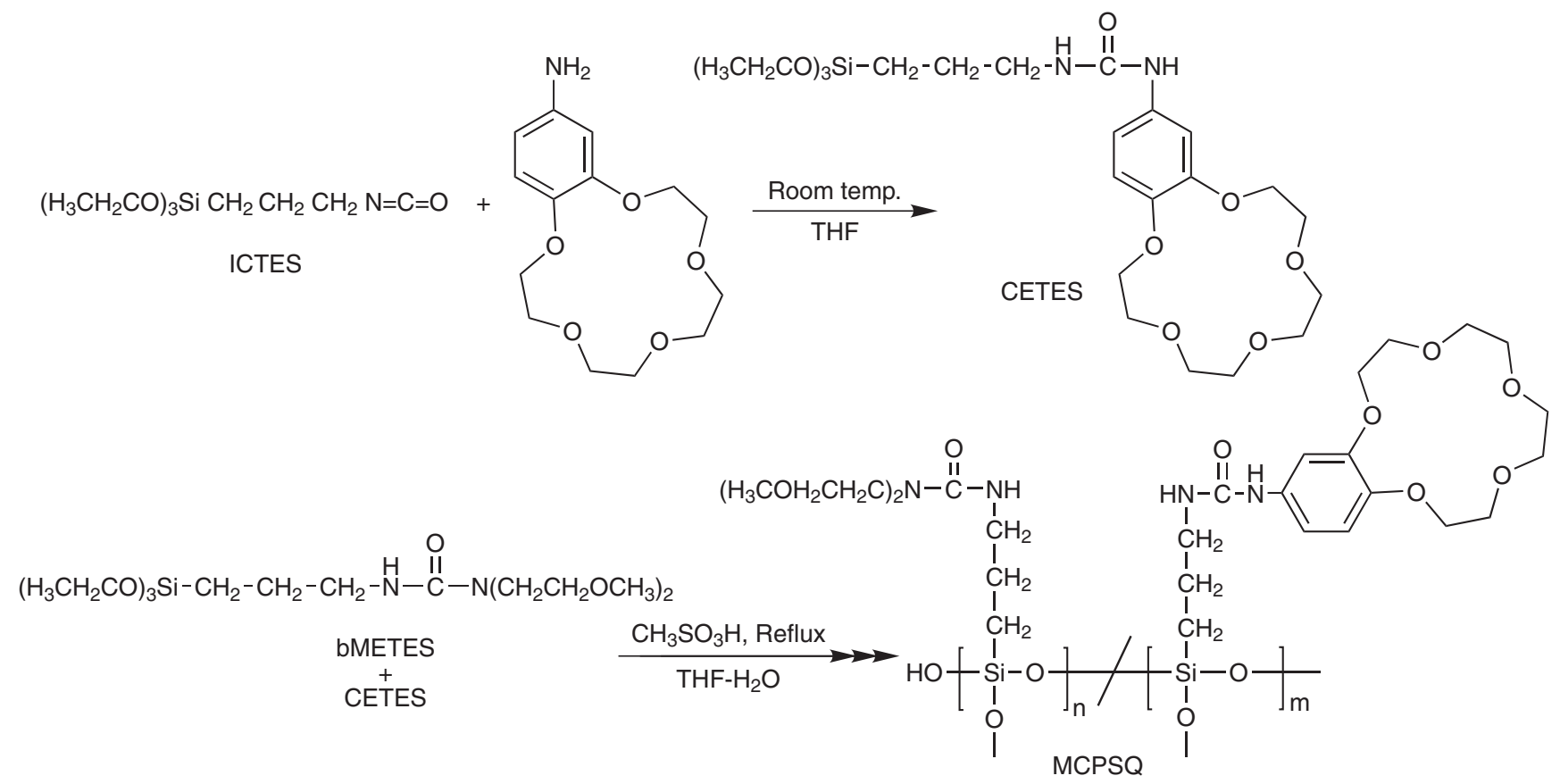

Scheme 1 Synthesis of MCPSQ.

PSQs. In this report, the results of the experiment to provide ion recognition in conjunction with the thermoresponsive property are mentioned, where the co-condensation of the silane coupling reagent having a bis(methoxyethyl)amide group (bMETES) with that having a 15-crown-5-ether ring (CETES) was used. The synthetic route to the PSQ with both functional groups (MCPSQ) is shown in Scheme 1. Furthermore, by the use of the ability of the crown ether to trap alkali metal ions, sodium salt of 4-phenylazobenzoic acid was introduced into MCPSQ to provide the additional stimulus-responsive property, such as photo-induced geometrical isomerization.

\section{EXPERIMENTAL PROCEDURE}

\section{General}

${ }^{1} \mathrm{H}$ nuclear magnetic resonance (NMR) and ${ }^{13} \mathrm{C}$ NMR spectra were obtained on a JEOL AL-300 and JNM A-500 spectrometer (JEOL, Tokyo, Japan) in $\mathrm{CDCl}_{3}$ or DMSO- $\mathrm{d}_{6}$. Infrared (IR) spectra were recorded on a JASCO FT/IR 230 spectrometer (JASCO, Tokyo, Japan). Gel permeation chromatographic (GPC) analysis was carried out to estimate the number-average molecular weight $\left(M_{\mathrm{n}}\right)$ and polydispersity $\left(M_{\mathrm{w}} / M_{\mathrm{n}}\right)$ on a Shimadzu LC-10VP chromatograph (Shimadzu, Kyoto, Japan) equipped with an evaporative light scattering detector. Three columns, such as Shim-pack GPC-80MD, -804D and -802D, were connected in series, and $\mathrm{N}, \mathrm{N}$-dimethylformamide was used as the eluent. Calibration was performed using poly(methyl methacrylate) standards. Tetrahydrofuran (THF) used for the reactions was distilled from sodium benzophenone ketyl before use. 4-aminobenzo-15-crown-5-ether, (3-isocyanatopropyl)triethoxysilane, $\mathrm{N}, \mathrm{N}$-bis(2-methoxyethyl)amine, methanesulfonic acid and the chlorides of alkali metal salts $(\mathrm{LiCl}, \mathrm{NaCl}, \mathrm{KCl})$ were used as supplied from commercial sources. bMETES was prepared according to the method discussed in a previous report. ${ }^{43}$

\section{Synthesis of CETES}

To a solution of 4-aminobenzo-15-crown-5-ether $(1.00 \mathrm{~g}, 3.53 \mathrm{mmol})$ in THF $(3.0 \mathrm{ml})$, (3-isocyanatopropyl)triethoxysilane $(0.87 \mathrm{~g}, 3.52 \mathrm{mmol})$ was added slowly at ambient temperature. After stirring for $24 \mathrm{~h}$, the resulting solution was evaporated under reduced pressure to concentrate, and the residue was poured into an excess amount of diethyl ether. The insoluble solid was washed with diethyl ether and dried at ambient temperature for $24 \mathrm{~h}$ under reduced pressure
$(<5 \mathrm{~mm} \mathrm{Hg})$ to obtain CETES as a solid $(1.57 \mathrm{~g}, 84 \%$ yield): IR ( $\mathrm{KBr}) 3340$ $(\mathrm{N}-\mathrm{H}), 2930,2880,1630(\mathrm{C}=\mathrm{O}), 1570(\mathrm{C}=\mathrm{O}, \mathrm{N}-\mathrm{H}), 1100(\mathrm{Si}-\mathrm{O}, \mathrm{C}-\mathrm{O}) \mathrm{cm}^{-1}$; ${ }^{1} \mathrm{H}$ NMR $\left(\mathrm{CDCl}_{3}, 500 \mathrm{MHz}\right) \delta 6.91\left(\mathrm{~d}, 1 \mathrm{H}, J=8.4 \mathrm{~Hz},-\mathrm{C}_{6} \mathrm{H}_{3}-\right), 6.58-6.70$ (m, 2H, - $\mathrm{C}_{6} \mathrm{H}_{3}-$ ), 5.80-6.00 (br, $\left.2 \mathrm{H},-\mathrm{NH}-\right), 4.02\left(\mathrm{t}, 4 \mathrm{H}, J=4.2 \mathrm{~Hz},-\mathrm{C}_{6} \mathrm{H}_{3}-\mathrm{O}-\right.$ $\left.\mathrm{CH}_{2}-\mathrm{CH}_{2}-\mathrm{O}-\right), 3.70-3.81\left(\mathrm{~m}, 18 \mathrm{H},-\mathrm{O}-\mathrm{CH}_{2}-,-\mathrm{OCH}_{2}-\mathrm{CH}_{3}\right), 3.13(\mathrm{~m}, 2 \mathrm{H},-\mathrm{NH}-$ $\left.\overline{\mathrm{CH}}_{2}{ }^{-}\right), .1 .54\left(\mathrm{~m}, 2 \mathrm{H},-\mathrm{CH}_{2}-\mathrm{CH}_{2}-\mathrm{CH}_{2}-\right), \overline{1} .14\left(\mathrm{t}, \overline{\mathrm{H}}, J=6.9 \mathrm{~Hz},-\mathrm{O}-\mathrm{CH}_{2}-\mathrm{CH}_{3}\right)$, $0 . \overline{5}\left(\mathrm{t}, 2 \mathrm{H}, J=8.1 \mathrm{~Hz},-\mathrm{Si}_{-}-\overline{\mathrm{CH}}_{2}\right) ;{ }^{13} \mathrm{C} \mathrm{NMR}\left(125 \mathrm{MHz}, \mathrm{CDCl}_{3}\right) \delta \overline{56.4}$ $(-\mathrm{C}=\mathrm{O}), 149.5\left(-\mathrm{C}_{6} \mathrm{H}_{3}-\mathrm{O}-\right), \overline{14} 5.6\left(-\mathrm{C}_{6} \mathrm{H}_{3}-\mathrm{O}-\right), 132.7 \quad\left(-\mathrm{C}_{6} \mathrm{H}_{3}-\mathrm{NH}-\right), 115.0$ $\left(\left(-\mathrm{C}_{6} \mathrm{H}_{3}-\right), 114.3\left(-\mathrm{C}_{6} \mathrm{H}_{3}-\right), 108.7\left(-\mathrm{C}_{6} \mathrm{H}_{3}-\right), 70.9\left(-\mathrm{CH}_{2}-\mathrm{O}-\right), 58.4\left(-\mathrm{O}-\mathrm{CH}_{2}-\right.\right.$ $\left.\mathrm{CH}_{3}\right), 43.1\left(-\mathrm{NH}-\overline{\mathrm{CH}}_{2}^{-}\right), 23.3\left(-\mathrm{O}-\mathrm{CH}_{2}-\underline{C H}_{3}\right), 18.3\left(-{ }^{-} \mathrm{CH}_{2}^{-}\right), 7.6\left(-\mathrm{Si}^{-} \underline{\mathrm{CH}}_{2^{-}}\right)$.

\section{Co-condensation of silane coupling reagent}

A solution of bMETES $(0.22 \mathrm{~g}, 0.57 \mathrm{mmol})$, CETES $(0.30 \mathrm{~g}, 0.57 \mathrm{mmol})$ and methanesulfonic acid $(0.010 \mathrm{~g}, 0.10 \mathrm{mmol}))$ in THF $(5 \mathrm{ml})$ and water $(1 \mathrm{ml})$ was refluxed for $24 \mathrm{~h}$. The resulting solution was concentrated by a rotary evaporator under reduced pressure and then an excess amount of diethyl ether was added to the residual oil. The precipitated solid was collected and dried at ambient temperature for $24 \mathrm{~h}$ in a vacuum oven under reduced pressure $(<5 \mathrm{~mm} \mathrm{Hg})$ to obtain MCPSQ $(0.38 \mathrm{~g}, 81 \%$ yield based on the bis(methoxyethylamide) group, $92 \%$ yield based on the crown ether group). The contents of the groups were calculated from the corresponding peak areas observed in the ${ }^{1} \mathrm{H}$ NMR spectrum, in which hexamethyldisiloxane was used as an internal standard: IR (KBr) 3360 (-NH-), 2980, 2920, 2880, 1630 (C=O), 1540, 1100 (Si-O, C-O), $630 \mathrm{~cm}^{-1} ;{ }^{1} \mathrm{H}$ NMR $\left(300 \mathrm{MHz}, \mathrm{CDCl}_{3}\right) \delta 7.21-6.10$ (br, $\left.-\mathrm{C}_{6} \underline{\mathrm{H}}_{3}{ }^{-}\right)$, 5.80-6.30 (br, -NH-), 3.98-3.66 (br, -O- $\mathrm{CH}_{2} \mathrm{CH}_{2}-\mathrm{O}-$ ), 3.41 (br, $\mathrm{CH}_{3} \mathrm{O}-\overline{\mathrm{CH}}_{2}-$ $\mathrm{CH}_{2}-\mathrm{N}-$ ), 3.25 (br, -O- $\mathrm{CH}_{3}$ ), 3.08 (br, - $\left.-\mathrm{NH}_{-} \mathrm{CH}_{2^{-}}\right), 1.53$ (br, $\left.-\mathrm{CH}_{2}-\right), 0.56$ (br, $\left.\mathrm{Si-C} \underline{H}_{2}\right) ;{ }^{13} \mathrm{C}$ NMR $\left(75 . \overline{4} 5 \mathrm{MHz}, \mathrm{CDCl}_{3}\right) \delta 1 \overline{56.5}(-\mathrm{C}=\mathrm{O}), 14 \overline{5.7}\left(-\mathrm{C}_{6} \mathrm{H}_{3}-\mathrm{O}-\right)$, $132.5\left(-\mathrm{C}_{6} \mathrm{H}_{3}-\mathrm{N}-\right), 115.0\left(-\mathrm{C}_{6} \mathrm{H}_{3^{-}}\right), 114.3\left(-\mathrm{C}_{6} \mathrm{H}_{3^{-}}\right), \overline{1} 08.6\left(-\mathrm{C}_{6} \mathrm{H}_{3^{-}}\right), 71.1(-\mathrm{O}-$ $\left.\mathrm{CH}_{2^{-}}\right), \overline{70.9}\left(-\mathrm{O}-\mathrm{CH}_{2}-\right), 59.8\left(-\mathrm{O}-\mathrm{CH}_{3}\right), 50.0\left(-\mathrm{N}-\mathrm{CH}_{2}-\right), \overline{40.1}\left(-\mathrm{NH}-\mathrm{CH}_{2^{-}}\right)$, $18.3\left(-\mathrm{CH}_{2}-\right), 7 . \overline{6}\left(-\mathrm{Si}^{-} \mathrm{CH}_{2}-\right) ; M_{\mathrm{n}}=5100, M_{\mathrm{w}} / M_{\mathrm{n}}=\overline{1.03}$; bis(methoxyethylamide) group $=1.22 \mathrm{mmol}$ equiv. per $\mathrm{g}$, crown ether group $=1.36 \mathrm{mmol}$ equiv. per $\mathrm{g}$.

\section{Measurement of transmittance (\%T)}

A $1.0 \mathrm{wt} \%$ solution of MCPSQ in distilled water, obtained from EYELA SA-2100A (Tokyo Rikakikai, Tokyo, Japan), was used for the measurement of transmittance $(\% \mathrm{~T})$ on a Shimadzu UV-1650 spectrophotometer equipped with a Peltier-type S-1700 thermostatic cell holder. In the measurements, the 
changes of $\% \mathrm{~T}$ were observed from a visible source at $800 \mathrm{~nm}$ through a $1-\mathrm{cm}$ quartz sample cell at the rate of $1{ }^{\circ} \mathrm{C} \mathrm{min}^{-1}$ during heating and cooling scans. The measurements were repeated at least three times on each sample until the observed curves reached good agreement.

By treatment of 4-phenylazobenzoic acid with sodium hydride in THF at ambient temperature, the sodium 4-phenylazobenzoate (AzANa) was obtained as a solid insoluble in acetone. In the measurements of the thermoresponsive behaviors of MCPSQ, $\mathrm{LiCl}, \mathrm{NaCl}, \mathrm{KCl}$ and AzANa were used as the additives.

Photochemical isomerization was performed by irradiation using a $300 \mathrm{~W}$ xenon lamp (Max-301; Asahi Spectra, Tokyo, Japan) equipped with optical filters of 334 and $440 \mathrm{~nm}$, respectively, for cis and trans isomerizations of the 4-phenylazobenzoate group. The changes in absorbance after photoirradiation were measured on $0.01 \mathrm{wt} \%$ aqueous solution of MCPSQ, in which 0.5 eq. of AzANa was added to the content of the crown ether group. The measurements for each compound were performed analogously.

\section{RESULTS AND DISCUSSION}

\section{Preparation and condensation of silane coupling reagent}

For the introduction of the ion recognition property, the use of a combination of thermoresponsive polymers with several ring sizes of crown ethers has been reported. ${ }^{32-35}$ In this work, the commercially available 4-aminobenzo-15-crown-5-ether, which was presumed to form a stable 'host-guest' complex with sodium ion $\left(\mathrm{Na}^{+}\right)$, was chosen. ${ }^{44}$ The formation of the silane coupling reagent with the 15 -crown-5-ether was attained by the reaction of $4^{\prime}$-aminobenzo15-crown-5-ether with (3-isocyanatopropyl)triethoxysilane. The coupling reagent obtained, CETES, was isolated with good yield, such as $84 \%$ as a solid insoluble in diethyl ether. The structure of CETES was confirmed by the spectral data, which showed the presence of both the triethoxysilyl group and the crown ether ring.

The co-condensation of bMETES and CETES in the mixed solvent of THF and water with a catalytic amount of methanesulfonic acid was carried out by the use of an equimolar amount of the silane coupling reagents. The co-condensation proceeded without formation of any crosslinked product to yield the amphiphilic MCPSQ. From the ${ }^{1} \mathrm{H}$ NMR spectral data of MCPSQ, in which the measurement was performed with hexamethyldisiloxane as an internal standard, the contents of the methoxyethylamide group and the crown ether group were estimated to be 1.22 and $1.36 \mathrm{mmol}$ eq. per g, respectively. The yields based on the former and latter groups were 81 and $92 \%$, respectively. In the ${ }^{1} \mathrm{H}$ NMR spectrum, the signals assigned to the methyl and methylene protons of the methoxyethyl group were observed at 3.25 and 3.41 p.p.m., respectively. The presence of the crown ether group was indicated by the signals in the region from 3.66 to 3.98 p.p.m., and those around 7 p.p.m. were due to benzene protons. The peak areas of these signals were used for the calculation of the contents of the respective groups. The signals of the protons bonded to nitrogen were thought to be present at $\sim 6$ p.p.m. as a broad peak. The ${ }^{1} \mathrm{H}$ NMR spectrum of MCPSQ is shown in Figure 1. The spectral data of ${ }^{13} \mathrm{C}$ NMR and IR also supported the formation of MCPSQ. However, the accurate structure of polysiloxane in MCPSQ could not be confirmed. In the IR spectrum of MCPSQ, as shown in Figure 2, the absorption of the hydroxyl group appears to be present besides the amide group. In our previous investigation on the formation of PSQ with a phenyl group, the ${ }^{29} \mathrm{Si}$ NMR spectrum showed signals corresponding to both the $\mathrm{T}^{2}$ and $\mathrm{T}^{3}$ structures. ${ }^{45}$ Therefore, the structure of the polysiloxane main chain was speculated to consist of incomplete, but not randomly crosslinked, ladder and cage structures. The $M_{\mathrm{n}}$ of MCPSQ was estimated to be 5100 by GPC. The presence of a unimodal peak in the chromatogram of GPC suggests that the condensations of CETES and bMETES proceed at almost the same rate. The GPC chromatogram is shown in Figure 3.

\section{Thermally reversible phase separation}

Thermoresponsive aggregation was indicated by the turbidity, measured as $\%$ Tat $800 \mathrm{~nm}$ under heating and cooling. All samples showed a reversible phase separation according to temperature. However, the cooling curves are excluded from the figures for ease of interpretation. The PSQ obtained from bMETES showed an LCST of $65^{\circ} \mathrm{C}$ in the 1 wt $\%$ aqueous solution, as previously reported. ${ }^{39}$ In the case of MCPSQ, the aggregation began at $20^{\circ} \mathrm{C}$. This seems to reflect the presence of the hydrophobic benzene ring of the introduced crown ether group. In the aqueous solution of the PSQ consisting only of a bMETES unit, the aggregation started at $65^{\circ} \mathrm{C}$ and was completed at $72{ }^{\circ} \mathrm{C}$, whereas a temperature range from 20 to $23^{\circ} \mathrm{C}$ was recorded for MCPSQ. This suggests that MCPSQ essentially possesses a good balance of hydrophilic and hydrophobic properties.

The ion recognition property of MCPSQ due to the presence of the crown ether group was evaluated by the addition of the alkali metal chlorides, $\mathrm{LiCl}, \mathrm{NaCl}$ and $\mathrm{KCl}$. The resulting behaviors are shown in



Figure $1{ }^{1} \mathrm{H}$ NMR spectrum of MCPSQ. 
Figure 4. The addition of an equivalent amount of $\mathrm{KCl}, \mathrm{LiCl}$ or $\mathrm{NaCl}$ to the crown ether group led to increases in the LCST of 24, 26 and $32^{\circ} \mathrm{C}$, respectively. When two equivalents of the salts were added to the aqueous solution, no change in LCST was observed in the cases of $\mathrm{LiCl}$ and $\mathrm{NaCl}$, but an increase in LCST of $31^{\circ} \mathrm{C}$ was recorded with the use of KCl. The highest LCST, obtained with the use of $\mathrm{NaCl}$, showed the selective formation of the complex of the crown ether with $\mathrm{Na}^{+}$.

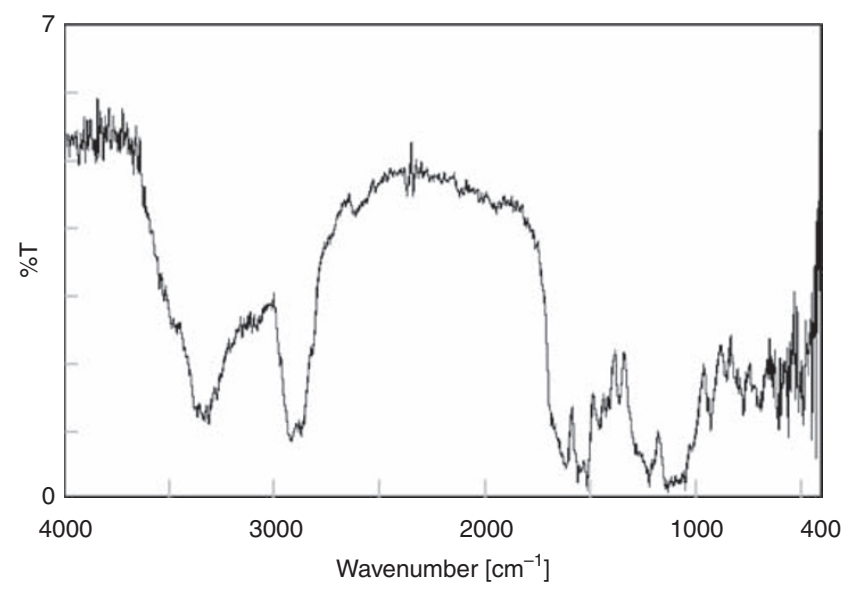

Figure 2 IR spectrum of MCPSQ.

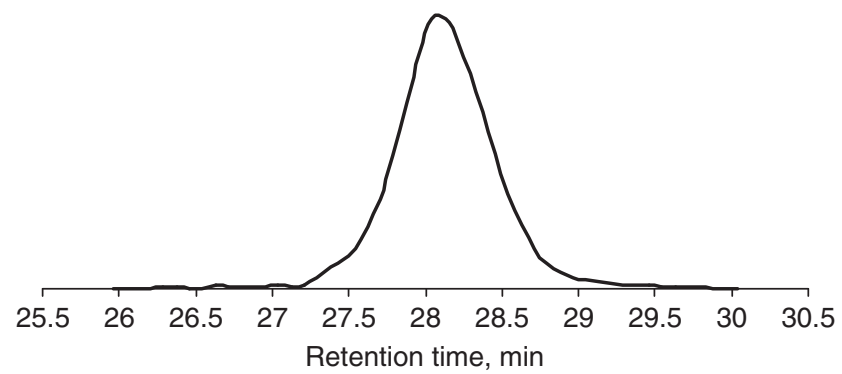

Figure 3 GPC chromatogram of MCPSQ.
This should form a hydrophilic environment in MCPSQ, in which a higher temperature should be required to remove water molecules. The increased LCST observed after the addition of an excess amount of $\mathrm{KCl}$ also seemed to be caused by the coordination, because 15-crown5-ether can coordinate with the larger ion species such as $\mathrm{K}^{+}$, although its ability is weaker in comparison with that of $\mathrm{Na}^{+} .44$ Furthermore, other sodium salts, such as sodium iodide and sodium bromide, were used as additives. The presence of the salts also led to increases in LCST of approximately $27^{\circ} \mathrm{C}$. However, no obvious effect on the thermoresponsive behavior caused by the difference between the anion species was detected.

Combinations of thermoresponsive polymers with a photoresponsive property have already been reported. In one previous example, the methacrylate polymer containing (4-phenylazo)phenoxy groups as the side chains showed an increase in LCST after ultraviolet irradiation at $346 \mathrm{~nm}$, at which the trans-azobenzene group should change to the cis-isomer. When the configuration was returned to trans-type by photoirradiation at $420 \mathrm{~nm}$, a depression in LCST of $3{ }^{\circ} \mathrm{C}$ was observed. ${ }^{46}$ By considering the results of the work, the effective coordination to $\mathrm{Na}^{+}$was applied to provide the additional photoresponsive property. For the introduction of the photoresponsive group into PSQ, AzANa was used as the additive in the aqueous solution of MCPSQ, and an efficient coordination to the crown ether was expected as shown in Scheme 2. When an equivalent of AzANa was added to the crown ether, an insoluble part was clearly present. Consequently, the amount of AzANa was adjusted to be half that of the equivalent for the crown ether. Under such conditions, the \% $\mathrm{T}$ of the $1 \mathrm{wt} \%$ aqueous solution of MCPSQ was increased to be 90\% at $20{ }^{\circ} \mathrm{C}$. At first, the photoresponsive trans-cis isomerization was examined by the use of a $0.01 \mathrm{wt} \%$ solution of MCPSQ with AzANa. The results are depicted in Figure 5, where the respective curves of MCPSQ and AzANa are also shown. After $1 \mathrm{~h}$ of photoirradiation at $334 \mathrm{~nm}$, the absorbance at $\sim 330 \mathrm{~nm}$ due to the trans-azobenzene group decreased. ${ }^{47}$ The absorbance increased to its original intensity after photoirradiation at $440 \mathrm{~nm}$ for $12 \mathrm{~h}$. These changes were repeated three times. In Figure 5, the behaviors observed the second time have been omitted for clarity. The changes in intensity seem to show the isomerization of the phenylazobenzene group. Analogous behavior was observed in our preliminary experiment conducted using AzANa. However, the complete isomerization of the group was not confirmed

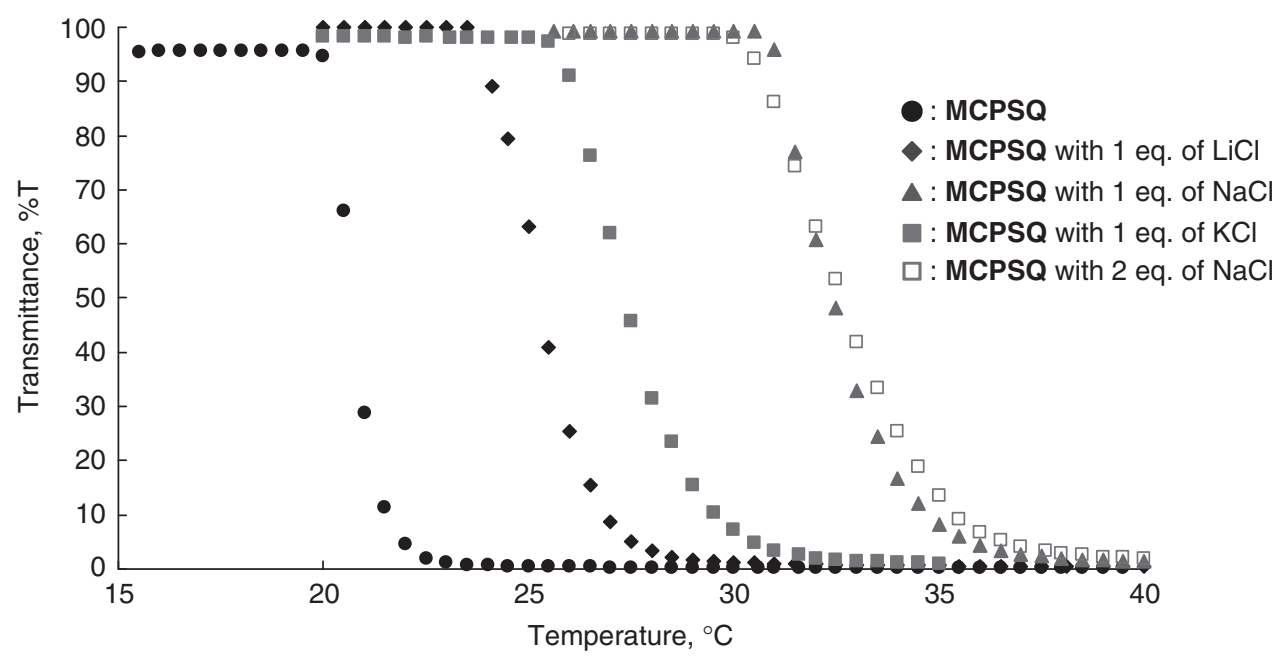

Figure 4 Temperature dependence of optical transmittance (\%T) at $800 \mathrm{~nm}$ for $1 \mathrm{wt} \%$ aqueous solution under heating $\left(1^{\circ} \mathrm{C} \mathrm{min}^{-1}\right)$. 


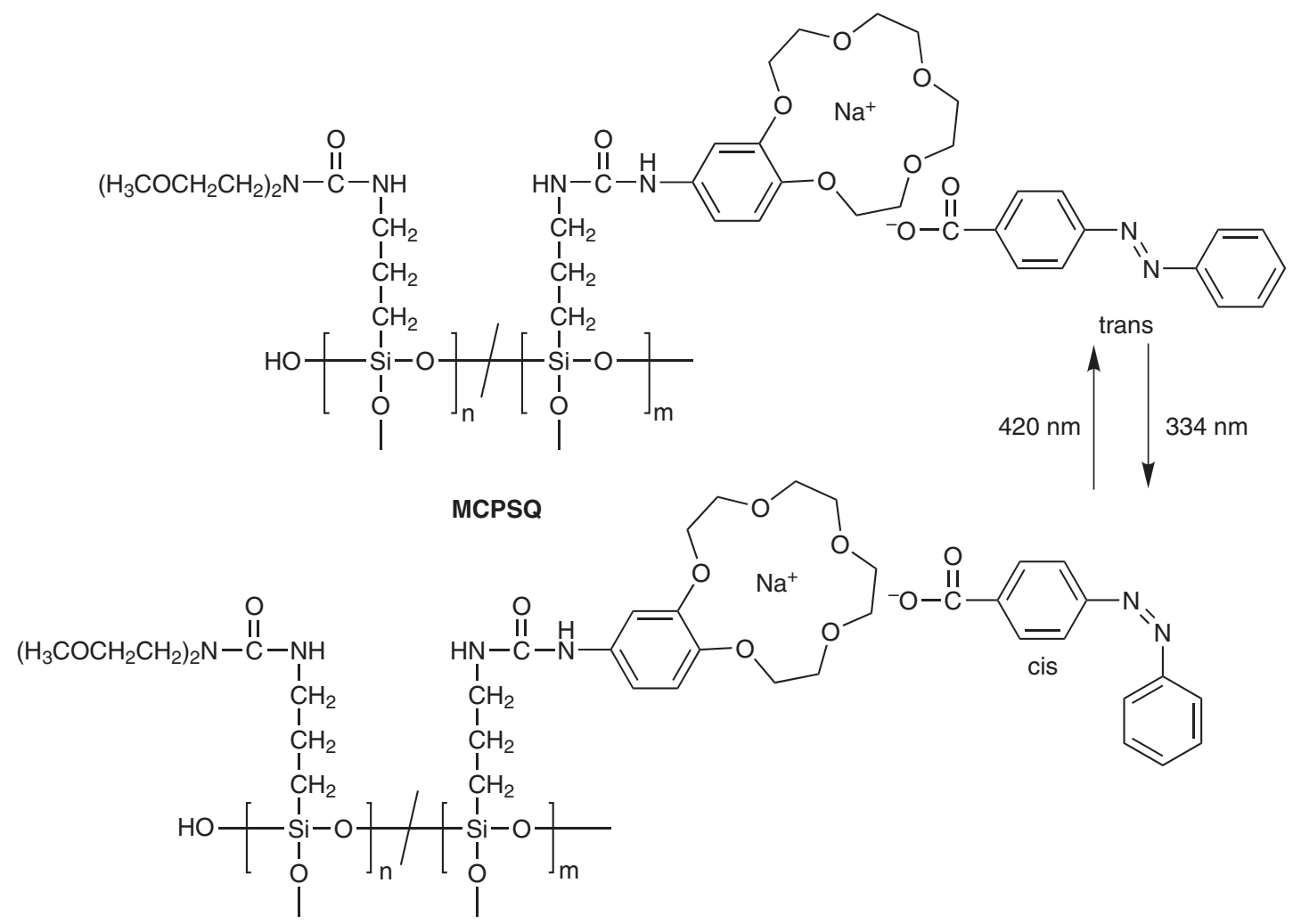

Scheme 2 MCPSQ with AzANa.

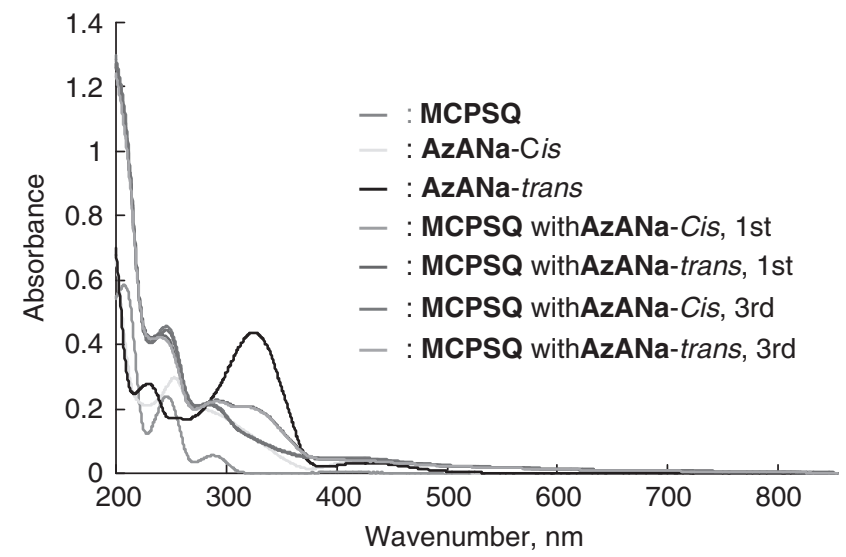

Figure 5 Ultraviolet-visable spectra of 0.01 wt\% aqueous solution of MCPSQ with AzANa after photoirradiation at $334 \mathrm{~nm}$ for cis-isomer and at $440 \mathrm{~nm}$ for trans-isomer.

because a smaller change in the intensity of the absorbance at $330 \mathrm{~nm}$ was observed with the photoisomerization compared with the changes found in the case of AzANa.

The thermoresponsive behaviors of the aqueous solution of MCPSQ containing AzANa are shown in Figure 6. An LCST of $27^{\circ} \mathrm{C}$ was recorded in the aqueous solution containing the original trans-isomer of the azobenzene group. This slight increase in LCST compared with the case with no additive supports the formation of the complex, which le to an increase in the hydrophilic property, irrespective of the presence of the hydrophobic azobenzene group. Next, the behavior was measured after photoirradiation at $334 \mathrm{~nm}$.

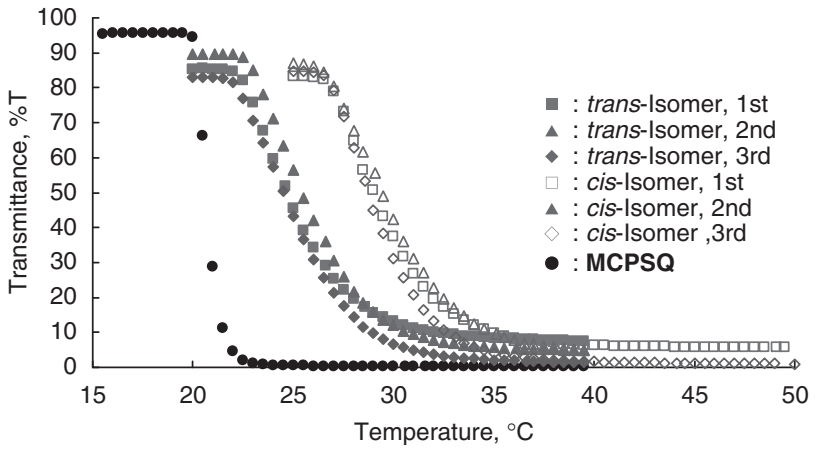

Figure 6 Temperature dependence of optical transmittance (\%T) at $800 \mathrm{~nm}$ for 1 wt\% aqueous solution of MCPSQ with 0.5 eq. of AzANa under heating $\left(1{ }^{\circ} \mathrm{C} \mathrm{min}^{-1}\right)$.

The LCST decreased to $23^{\circ} \mathrm{C}$ after the irradiation. The solution was photoirradiated at $440 \mathrm{~nm}$ to return to the trans-azobenzene group. After this treatment, an LCST of $\sim 27^{\circ} \mathrm{C}$ was observed. In the three repeated photochemical isomerizations, almost identical changes in behavior were observed. These observations support the claim that the azobenzene group brought about the photoresponsive property as well as the thermoresponsive one. In addition, the transformation into the trans-isomer of the azobenzene group seemed to increase the hydophilicity of MCPSQ, but the reason for the increase of LCST is unclear. Furthermore, the location and the situation of the phenylazobenzoate group around the MCPSQ molecule has not been clarified, but it is at least apparent that the group contributes to the enhancement of the hydrophilic property of MCPSQ. Thus, MCPSQ was provided with combined and mutually interacting stimulus-responsive properties. 


\section{Conclusion}

The use of bMETES for the co-condensation of CETES enabled the easy preparation of the multi-stimulus-responsive PSQ derivative. The obtained MCPSQ was provided with the ion recognition property, which was related to the thermoresponsive behavior. The introduction of the 15-crown-5-ether group resulted in increases in the hydrophilic property and in the aggregation temperature of MCPSQ in the presence of $\mathrm{Na}^{+}$. With the use of sodium phenylazobenzoate, the thermoresponsive behavior supported the efficient holding of the functional acid. In this example, the photochemical isomerization of the azobenzene group resulted in a change in the LCST. This is an example in which the combined thermo- and photoresponsive properties were observed.

Thus, the procedure using the silane coupling reagents as building blocks was shown to be a convenient and practical strategy for the synthesis of multi-stimulus-responsive PSQ derivatives. Such silane coupling reagents appear to be useful for conferring particular functions on gel materials through surface coating or co-gelation, by which the design of molecular- and/or nano-sized structures is possible.

1 Baney, R. H. \& Cao, X. In Silicon-Containing Polymers, (eds. Johns, R.G., Ando, W., Chojnowski, J.) (Kluwer, Dordrecht, 2000).

2 Sprung, M. M. \& Guenther, F. O. The hydrolysis of $n$-amyltriethoxysilane and phenyltrimethoxysilane. J. Polym. Sci. 28, 17-34 (1958).

3 Brown, Jr. J.F., Vogt, Jr. L.H., Katchman, A., Eustance, J. W., Kaiser, K. M. \& Krantz, K. W. Double chain polymers of phenylsilsesquioxane. J. Am. Chem. Soc. 82, 6194-6195 (1960).

4 Roy, D. A. \& Shea, K. J. Bridged polysilsesquioxanes. Highly porous hybrid organicinorganic materials. Chem. Rev. 95, 1431-1442 (1995)

5 Kondo, T., Yoshi, K., Horie, K. \& Itoh, M. Photoprove study of siloxane polymers. 3. Local free volume of polymethylsilsesquioxane proved by photoisomerization of azobenzene. Macromolecules 33, 3650-3658 (2000).

6 Yamamoto, S., Yasuda, N., Ueyama, A., Adachi, H. \& Ishikawa, M. Mechanism for the formation of poly(phenylsilsesquioxane). Macromolecules 37, 2775-2778 (2004).

7 Gunji, T., lizuka, Y., Arimitsu, K. \& Abe, Y. Preparation and properties of alkoxy (methyl)silsesquioxanes as coating agents. J. Polym. Sci., Part A: Polym. Chem. 42, 3676-3684 (2004).

8 Chauhan, B. P. S. \& Latif, U. Inorganic/organic hybrid nanoreactors based on cyclic and cubic siloxane scaffolds. Macromolecules 38, 6231-6235 (2005).

9 Gozdz, A. S. Progress in the chemistry of organosilicon resists. Polym. Adv. Tech. 5, 70-78 (1993).

10 Chang, C.- L. \& Ma, C.- C. M. Synthesis, characterization, and properties of novel ladderlike phosphorus-containing polysilsesquioxanes. J. Polym. Sci., Polym. Chem. 41, 1371-1379 (2003).

11 Krishnan, P. S. G. \& He, C. Synthesis, characterization, and polymerization kinetics of novel ladder-like polysilsesquioxanes containing side-chain propyl methacrylate groups. Macromol. Chem. Phys. 204, 531-539 (2003).

12 Pyun, J. \& Matyjaszewski, K. Synthesis of nanocomposite organic/inorganic hybrid materials using controlled/'living' radical polymerization. Chem. Mater. 13, 3436-3448 (2001).

13 Kim, K.- M., Keum, D.- K. \& Chujo, Y. Organic-inorganic polymer hybrids using polyoxazoline initiated by functionalized silsesquioxane. Macromolecules 36 , 867-875 (2003).

14 Cardoen, G. \& Coughlin, E. B. Hemi-telechelic polystyrene-POSS copolymers as model systems for the study of well-defined inorganic/organic hybrid materials. Macromolecules 37, 5123-5126 (2004).

$15 \mathrm{Fu}$, B. X., Lee, A. \& Haddad, T. S. Styrene-butadiene-styrene triblock copolymers modified with polyhedral oligomeric silsesquioxanes. Macromolecules 37, 5211-5218 (2004).

16 Ohno, K., Sugiyama, S., Koh, K., Tsujii, Y., Fukuda, T., Yamahiro, M., Oikawa, H., Yamamoto, Y., Ootake, N. \& Watanabe, K. Living radical polymerization by polyhedral oligomeric silsesquioxane-holding initiators: precision synthesis of tadpole-shaped organic/inorganic hybrid polymers. Macromolecules 37, 8517-8522 (2004).

17 Heskins, M. \& Guillet, J. E. Solution properties of poly( $N$-isopropylacrylamide). J. Macromol. Sci. Chem. 2, 1441-1455 (1968).

18 Fujishige, S., Kubota, K. \& Ando, I. Phase transition of aqueous solutions of poly( $N$-isopropylacrylamide) and poly( $N$-isopropylmethacrylamide). J. Phys. Chem. 93, 3311-3313 (1989).

19 Chen, G. H. \& Hoffman, A. S. Graft copolymers that exhibit temperature induced phase transitions over a wide range of $\mathrm{pH}$. Nature 373, 49-52 (1995).
20 Pelton, R. Temperature-sensitive aqueous microgels. Adv. Colloid. Interface Sci. 85, 1-33 (2000).

21 Ray, B., Isobe, Y., Matsumoto, K., Habaue, S., Okamoto, Y., Kamigaito, M. \& Sawamoto, M. RAFT polymerization of $\mathrm{N}$-isopropylacrylamide in the absence and presence of $\mathrm{Y}(\mathrm{OTf})_{3}$ : simultaneous control of molecular weight and tacticity. Macromolecules 37, 1702-1710 (2004).

22 Meyer, S. \& Richtering, W. Influence of polymerization conditions on the structure of temperature-sensitive poly( $\mathrm{N}$-isopropylacrylamide) microgels. Macromolecules $\mathbf{3 8}$, 1517-1519 (2005).

$23 \mathrm{Kim}$, K. S. \& Vincent, B. pH and temperature-sensitive behaviors of poly(4-vinyl pyridine-co- $N$-isopropyl acrylamide) microgels. Polym. J. 37, 565-570 (2005).

24 Moriya, O., Kuga, M., Yamamoto, S., Kashio, M., Kamejima, A. \& Sugizaki, T. Preparation of polysilsesquioxane grafted thermoresponsive polymer by use of mercapto group. Polymer 47, 1837-1844 (2006).

25 Yamamoto, S., Minami, F., Masuda, T., Moriya, O., Kashio, M. \& Sugizaki, T. Preparation of polysilsesquioxane having dimethylamino group and grafted thermoresponsive polymer. Polymer 47, 7693-7701 (2006).

26 Masuda, T., Yamamoto, S., Moriya, O., Kashio, M. \& Sugizaki, T. Preparation of amphiphilic polysilsesquioxane by grafting of block copolymer of acrylamide monomers. Polym. J. 39, 220-229 (2007).

27 Wohlrab, S. \& Kuckling, D. Multisensitive polymers based on 2-vinylpyridine and $\mathrm{N}$-isopropylacrylamide. J. Polym.Sci., Part A: Polym. Chem. 39, 3797-3804 (2001).

28 Rossi, N. A. A., Jadhav, V., Lai, B. F. L., Maiti, S. \& Kizhakkedathu, J. N. Stimuliresponsive cationic terpolymers by RAFT polymerization: Synthesis, characterization, and protein interaction studies. J. Polym. Sci., Part A: Polym. Chem. 46, 4021-4029 (2008).

29 Mujumdar, S. K. \& Siegel, R. A. Introduction of pH-sensitivity into mechanically strong nanoclay composite hydrogels based on $\mathrm{N}$-isopropylacrylamide. J. Polym. Sci., Part A: Polym. Chem. 46, 6630-6640 (2008).

30 Lee, H.-i.I., Pietrasik, J. \& Matyjaszewski, K. Photo-tunable temperature-responsive molecular brushes prepared by ATRP. Macromolecules 39, 3914-3920 (2006).

31 Edahiro, J., Sumaru, K., Takagi, T., Shinbo, T., Kanamori, T. \& Sudoh, M. Analysis of photo-induced hydration of a photochromic poly ( $\mathrm{N}$-isopropylacrylamide)-Spiropyran copolymer thin layer by quartz crystal microbalance. Eur. Polym. J. 44, 300-307 (2008).

32 Irie, M., Misumi, Y. \& Tanaka, T. Stimuli-responsive polymers: chemical induced reversible phase separation of an aqueous solution of poly $(N$-isopropylacrylamide $)$ with pendent crown ether groups. Polymer 34, 4531-4535 (1993).

33 Yamaguchi, T., Ito, T., Sato, T., Shinbo, T. \& Nakao, S. Development of a fast response molecular recognition ion gating membrane. J. Am. Chem. Soc. 121, 4078-4079 (1999).

34 Ito, T. \& Yamaguchi, T. Controlled release of model drugs through a molecular recognition ion gating membrane in response to a specific ion signal. Langmuir 22, 3945-3949 (2006).

35 Ju, X.- J., Liu, L., Xie, R., Niu, C. H. \& Chu, L.- Y. Dual thermo-responsive and ionrecognizable monodisperse microspheres. Polymer 50, 922-929 (2009).

36 Dimitrov, I., Trzebicka, B., Müller, A. H. E., Dworak, A. \& Tsvetanov, C. B. Thermosensitive water-soluble copolymers with doubly responsive reversibly interacting entities. Prog. Polym. Sci. 32, 1275-1343 (2007).

37 Budhiall, B. M., Marquez, M. \& Velev, O. D. Microwave, photo- and thermally responsive PNIPAm-Gold nanoparticle microgels. Langmuir 24, 11959-11966 (2008).

38 Wohlrab, S. \& Kuckling, D. Multisensitive polymers based on 2-vinylpyridine and $\mathrm{N}$-isopropylacrylamide. J. Polym. Sci., Part A: Polym. Chem. 39, 3797-3804 (2001).

39 Skrabania, K., Kristen, J., Laschewsky, A., Akdemir, Ö., Hoth, A. \& Lutz, J.- F. Design, synthesis, and aqueous aggregation behavior of nonionic single and multiple thermoresponsive polymers. Langnuir 23, 84-93 (2007).

40 Park, J. S., Akiyama, Y., Winnik, F. M. \& Kataoka, K. Versatile synthesis of endfunctionalized thermoresponsive poly(2-isopropyl-2-oxazoline). Macromolecules 37, 6786-6792 (2004).

41 Iwasaki, Y., Wachiralarpphaithoon, C. \& Akiyoshi, K. Novel thermoresponsive polymers having biodegradable phosphoester backbones. Macromolecules 40, 8136-8138 (2007).

42 Seno, K., Kanaoka, S. \& Aoshima, S. Thermosensitive diblock copolymers with designed molecular weight distribution: synthesis by continuous living cationic polymerization and micellization behavior. J. Polym. Sci., Polym. Chem. 46, 2212-2221 (2008).

43 Matsuoka, T., Yamamoto, S. \& Mroiya, O. A new amphiphilic and thermoresponsive polysilsesquioxane having alokoxyethylamide group. Chem. Lett. 37, 772-773 (2008).

44 Walkowiak, W., Kang, S. I., Stewart, L. E., Ndip, G. \& Bartsch, R. A. Effect of ring size variation within lipophilic crown ether carboxylic acids on the selectivity and efficiency of competitive alkali-metal cation solvent extraction into chloroform. Anal. Chem. 62, 2022-2026 (1990).

45 Matsubara, Y., Konishi, W., Sugizaki, T. \& Moriya, O. Synthesis of poly(phenylsilsesquioxane) having organostannyl groups. J. Polym. Sci., Part A: Polym. Chem. 39, 2125-2133 (2001).

46 Ravi, P., Sin, S. L., Gan, L. H., Gan, Y. Y., Tam, K. C., Xia, X. L. \& Hu, X. New water soluble azobenzene-containing diblock copolymers: synthesis and aggregation behavior. Polymer 46, 137-146 (2003).

47 Uchida, E. \& Kawatsuki, N. Influence of wavelength of light on photoinduced orientation of azobenzene-containing polymethacrylate film. Polym. J. 38, 724-731 (2006). 